\title{
Comparative assessment of insecticide resistance phenotypes in two major malaria vectors, Anopheles funestus and Anopheles arabiensis in south-eastern Tanzania
}

Polius G. Pinda ${ }^{1 *}$ (1), Claudia Eichenberger ${ }^{1,4+}$, Halfan S. Ngowo ${ }^{1,5}$, Dickson S. Msaky ${ }^{1}$, Said Abbasi ${ }^{1}$, Japhet Kihonda', Hamis Bwanaly ${ }^{1}$ and Fredros O. Okumu ${ }^{1,2,3,5^{*}}$

\begin{abstract}
Background: Long-lasting insecticide-treated nets (LLINS) and indoor residual spraying (IRS) have greatly reduced malaria transmission in sub-Saharan Africa, but are threatened by insecticide resistance. In south-eastern Tanzania, pyrethroid-resistant Anopheles funestus are now implicated in $>80 \%$ of malaria infections, even in villages where the species occurs at lower densities than the other vector, Anopheles arabiensis. This study compared the insecticide resistance phenotypes between the two malaria vectors in an area where pyrethroid-LLINs are widely used.

Methods: The study used the World Health Organization (WHO) assays with $1 \times, 5 \times$ and $10 \times$ insecticide doses to assess levels of resistance, followed by synergist bioassays to understand possible mechanisms of the observed resistance phenotypes. The tests involved adult mosquitoes collected from three villages across two districts in southeastern Tanzania and included four insecticide classes.

Findings: At baseline doses $(1 \times)$, both species were resistant to the two candidate pyrethroids (permethrin and deltamethrin), but susceptible to the organophosphate (pirimiphos-methyl). Anopheles funestus, but not An. arabiensis was also resistant to the carbamate (bendiocarb). Both species were resistant to DDT in all villages except in one village where An. arabiensis was susceptible. Anopheles funestus showed strong resistance to pyrethroids, surviving the $5 \times$ and $10 \times$ doses, while An. arabiensis reverted to susceptibility at the $5 \times$ dose. Pre-exposure to the synergist, piperonyl butoxide (PBO), enhanced the potency of the pyrethroids against both species and resulted in full susceptibility of An. arabiensis (> 98\% mortality). However, for An. funestus from two villages, permethrin-associated mortalities after pre-exposure to PBO only exceeded $90 \%$ but not $98 \%$.

Conclusions: In south-eastern Tanzania, where An. funestus dominates malaria transmission, the species also has much stronger resistance to pyrethroids than its counterpart, An. arabiensis, and can survive more classes of insecticides. The pyrethroid resistance in both species appears to be mostly metabolic and may be partially addressed using synergists, e.g. PBO. These findings may explain the continued persistence and dominance of An. funestus despite widespread use of pyrethroid-treated LLINs, and inform new intervention choices for such settings. In short and
\end{abstract}

\footnotetext{
*Correspondence: ppinda@ihi.or.tz; fredros@ihi.or.tz

${ }^{\dagger}$ Polius G. Pinda and Claudia Eichenberger contributed equally to this work

${ }^{1}$ Environmental Health and Ecological Sciences Department, Ifakara Health Institute, Morogoro, United Republic of Tanzania

Full list of author information is available at the end of the article
}

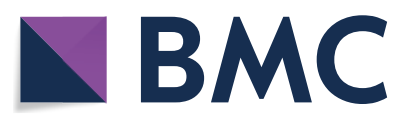

(c) The Author(s) 2020. This article is licensed under a Creative Commons Attribution 4.0 International License, which permits use, sharing, adaptation, distribution and reproduction in any medium or format, as long as you give appropriate credit to the original author(s) and the source, provide a link to the Creative Commons licence, and indicate if changes were made. The images or other third party material in this article are included in the article's Creative Commons licence, unless indicated otherwise in a credit line to the material. If material is not included in the article's Creative Commons licence and your intended use is not permitted by statutory regulation or exceeds the permitted use, you will need to obtain permission directly from the copyright holder. To view a copy of this licence, visit http://creativeco mmons.org/licenses/by/4.0/. The Creative Commons Public Domain Dedication waiver (http://creativecommons.org/publicdomain/ zero/1.0/) applies to the data made available in this article, unless otherwise stated in a credit line to the data. 
medium-term, these may include PBO-based LLINs or improved IRS with compounds to which the vectors are still susceptible.

Keywords: Insecticide resistance, Anopheles funestus, PBO, Ifakara health institute, Tanzania

\section{Background}

Effective use of long-lasting insecticide-treated nets (LLINs) and indoor residual spraying (IRS) has tremendously reduced malaria transmission in sub-Saharan Africa [1, 2]. Despite this reduction, malaria transmission continues in several areas, driven by mosquitoes that are either physiologically [3-5] or behaviourally resistant [610] to current insecticide-based interventions. Resistance to commonly used pyrethroids has also necessitated a change of insecticide classes for IRS to either carbamates, organophosphates or more recently neonicotinoids approved by the World Health Organization (WHO) [11]. Similarly new insecticide-treated nets (ITNs) are being developed that contain either multiple insecticide classes [12] or pyrethroids and synergists [13, 14], and are expected to improve the control of resistant mosquitoes.

Mosquito resistance involves different mechanisms, through which they can withstand exposures to insecticides. These include metabolic resistance, target-site resistance, behavioural resistance, and cuticular resistance [15-17]. The discriminating concentration is used to evaluate the phenotypic resistance which when detected, the level of resistance can be subsequentlly determined by using intensity assays. The intensity assays uses the $5 \times$ and $10 \times$ discriminating concentration in a stepwise manner aiming at providing the information on the range of resistance present in a target vector [18]. Mosquitoes that express metabolic forms of resistance produce large quantities of enzymes or alternate the enzyme catalytic centre to efficiently detoxify the insecticide. The specific enzymes include monooxygenases (i.e. cytochrome P450s), which detoxify pyrethroids and carbamates, glutathione-S-transferases (GSTs), which detoxify organochlorides like DDT [17], and esterases, which detoxify pyrethroids and organophosphates $[19,20]$. The degree to which the enzymatic proteins are expressed, and the level of resistance can be assessed using quantitative polymerase chain reaction (qPCR). Phenotypic assays use synergists, such as piperonyl butoxide (PBO), which enhance the potency of an insecticide by inhibiting the enzymes responsible for the insecticide metabolism [21]. On the other hand, some mosquitoes may have one or multiple target-site mutations due to modification of protein receptors usually targeted by insecticides (e.g. the voltage-gated sodium channels targeted by pyrethroids and organochlorides), thereby blocking or reducing the effectiveness of the insecticides [22-24]. Recently, scientists have also demonstrated that a sensory appendage protein (SAP2) enriched in the legs of malaria-carrying mosquitoes can also confer resistance to insecticides, thus allowing these mosquitoes to survive contact with ITNs [25].

Different Anopheles species have diverse levels of competencies in pathogen transmission, and also respond different to interventions based on their behaviour and physiology [26, 27]. With the rise of insecticide resistance in the vector populations, the choice of interventions will depend on characteristics of the local vectors. Comprehensive understanding of the distribution and underlying mechanisms of insecticide resistance is, therefore, important for planning and implementing vector control interventions.

In the villages of south-eastern Tanzania, where Anopheles funestus have been reported to be implicated in most of the ongoing malaria transmission [28-30], signs of resistance to most public health pesticides have been observed. Anopheles funestus also appears to survive longer than other co-existing vector species (parity rates are higher than Anopheles arabiensis) [28]. However, since the species is highly anthropophagic (prefers to blood-feed on humans over that of other vertebrates) $[31,32]$ and endophilic (prefers to bite indoors) [33], one would expect its populations and transmission activity to have been significantly reduced by ITNs now widely used in Tanzania for more than one decade [34-37]. Indeed, historical evidence from both East and Southern Africa suggests that effective insecticide-based indoor interventions can eliminate An. funestus on a local scale [38, 39]. Anopheles gambiae sensu stricto (s.s.), which is generally considered the most competent malaria vector, shares similar behaviours with An. funestus, i.e. high degree of anthropophily and endophilly [31, 32, 40]. However, $A n$. gambiae s.s. unlike An. funestus has been highly impacted by ITNs in Kenya and Tanzania [41-43].

An important question, therefore, is why and how $A n$. funestus, despite being highly anthropophagic and endophilic, survived the ITN onslaught, and why it continues to mediate most malaria transmission in rural southeastern Tanzania despite co-occurrence with a different malaria vector species, An. arabiensis. One hypothesis has been that An. funestus expresses higher intensities of resistance to most of the commonly used insecticides in comparison to other malaria vectors and is, therefore, far less impacted by insecticidal interventions. A metaanalysis of various datasets has verified this phenomenon 
at global scale [44], but specific field tests comparing resistance intensities in the different vector species are limited. As shown by Kaindoa et al. in a study conducted in south-eastern Tanzania, An. funestus was resistant to pyrethroids, organochlorides, and carbamates [28]. Another study from the same study area demonstrated that resistance of An. arabiensis to diagnostic insecticide concentrations varied between nearby locations and seasons [45]. However, the intensity and mechanisms of these resistance phenotypes were not compared between species.

This study, therefore, compared the intensities and knockdown time of insecticide-resistance between the two main malaria vectors, An. funestus and An. arabiensis, in rural south-eastern Tanzania. Potential involvement of metabolic resistance and insecticide potency enhancement by Piperonyl Butoxide (PBO) synergists was also assessed.

\section{Methods}

\section{Study site}

Mosquito collections were done in three different villages, namely; Ikwambi $\left(7.98033^{\circ} \mathrm{S}, 36.81701^{\circ} \mathrm{E}\right)$ and Sululu $\left(8.00324^{\circ} \mathrm{S}, 36.83118^{\circ} \mathrm{E}\right)$ in Kilombero district, and Tulizamoyo village $\left(8.35747^{\circ} \mathrm{S}, 36.70664^{\circ} \mathrm{E}\right)$ in Ulanga district, south-eastern Tanzania (Fig. 1). The main malaria vectors in this area include An. arabiensis and
An. funestus, with the latter driving more than $80 \%$ of the malaria transmission $[28,29]$. This area has had high coverage of pyrethroid-treated nets for several years, but no IRS is implemented. The villages are all in low altitude areas, rising not more than $500 \mathrm{~m}$ above sea level. Mean daily temperatures are $20-33{ }^{\circ} \mathrm{C}$, annual rainfall, 1200 $1800 \mathrm{~mm}$ and relative humidity ranged between 24 and $97 \%$ [46, 47]. Most community members here are farmers, cultivating rice, maize and other crops in the Kilombero river valley.

\section{Mosquito collection}

The WHO protocol for insecticide susceptibility tests [18] was used with slight modifications to conduct the basic bioassays and the resistance intensity assays. Since An. funestus mosquitoes were difficult to find as larvae across all the study villages, young nulliparous adult females of both An. funestus and An. arabiensis were used instead of larval collections. Mosquitoes were collected from September 2018 to November 2019 using CDC light traps [48]. Collections were done from 07.00 p.m. to 07.00 a.m. each night. To maximize probabilities of getting young unfed nulliparous females, houses near the edges of the villages and near potential habitats were selected for collections, based on previously-described heterogeneity of malaria transmission [49].

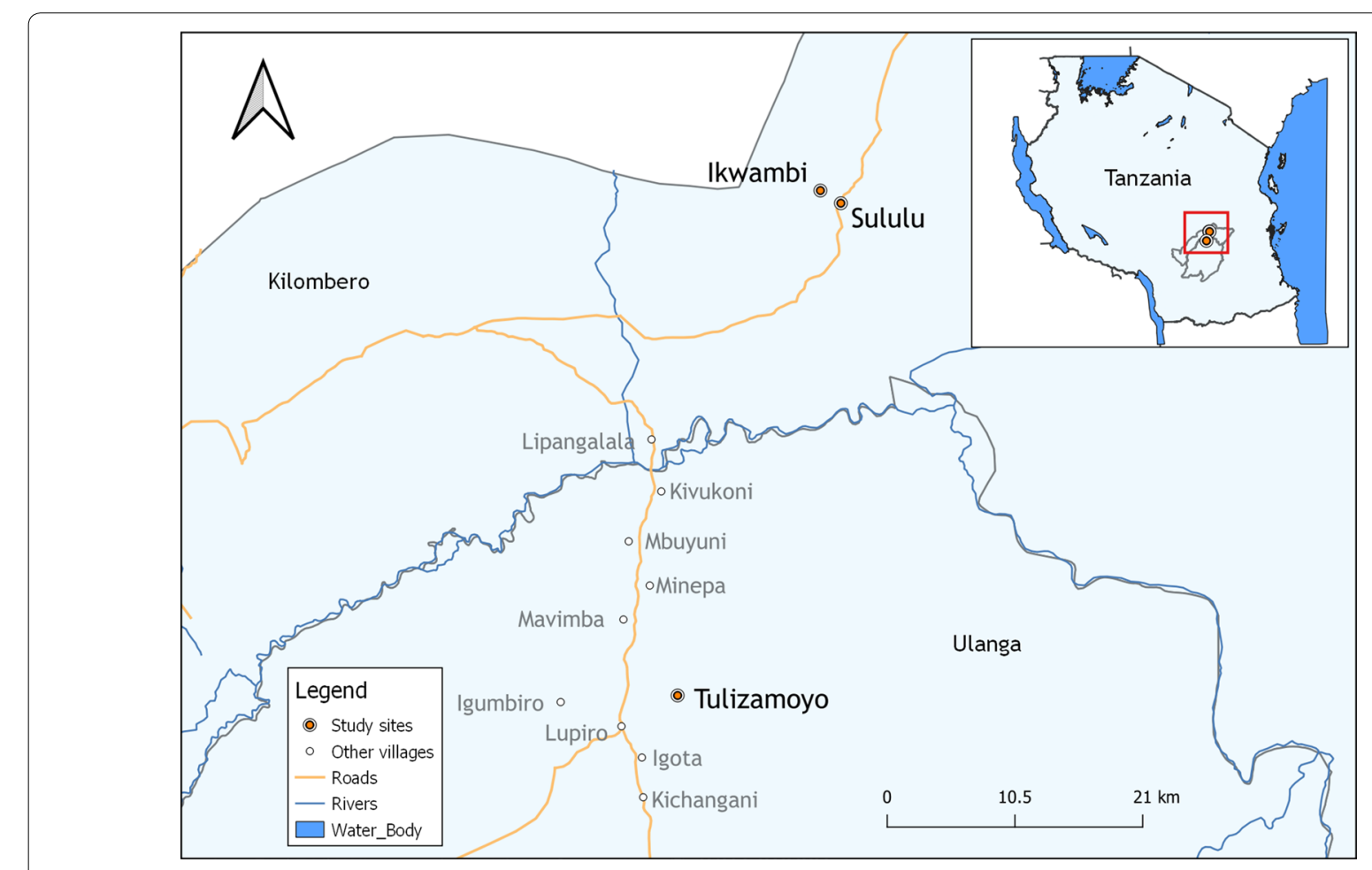

Fig. 1 Locations of the study sites in Kilombero and Ulanga districts, where adult mosquito collections were performed 
The traps were hung beside human occupied bed nets [50], but with extended catch bags to improve survival of the mosquitoes for subsequent assays. Each morning, after collections, the mosquitoes were transported to the Ifakara Health Institute's mosquito biology laboratory, VectorSphere, in Ifakara and maintained at $27 \pm 2{ }^{\circ} \mathrm{C}$ and $80 \pm 10 \%$ relative humidity for $24 \mathrm{~h}$ to acclimatize as previously described [45]. During the acclimatization period, mosquitoes were supplied with $10 \%$ glucose solution. The mosquitoes were identified morphologically using the Gillies and Coetzee identification key [51], and non-target species were discarded. Tests were conducted using only non-blood-fed An. funestus and An. arabiensis females.

\section{Bioassays}

This study involved three steps: (i) susceptibility assays to examine phonotypic resistance against standard insecticide doses, (ii) tests to assess intensity of resistance against chemicals to which resistance had been detected at baseline level, and (iii) tests using synergists to assess possible mechanisms of the observed reistance.

Baseline insecticide susceptibility bioassays were done according to WHO guidelines [18]. Candidate insecticides were selected from four classes as follows: organophosphate $(0.25 \%$ pirimiphos-methyl), organochloride (4\% DDT), carbamate ( $0.1 \%$ bendiocarb), pyrethroid type I ( $0.75 \%, 3.75$ and $7.5 \%$ permethrin) and pyrethroid type II ( $0.05 \%, 0.25$ and $0.5 \%$ deltamethrin). In each test, 120 mosquitoes were exposed to the insecticide-impregnated papers, and oil-impregnated papers as controls. Each test comprised six replicates (four treatments and two controls) with the total of 120 mosquitoes. Mosquitoes were exposed for $1 \mathrm{~h}$ and the knockdown time recorded at an interval of 10, 15, 20, 30, 40, 50, $60 \mathrm{~min}$. They were then transferred to holding tubes, provided with $10 \%$ glucose solution, and their mortality recorded after $24 \mathrm{~h}$.

Where resistance was observed in the baseline assays with standard diagnostic doses (i.e. $1 \times$ ), additional tests were done to assess intensities of the resistance using $5 \times$ and $10 \times$ multiplicative doses of the insecticides. These included tests against $3.75 \%$ and $7.5 \%$ permethrin, and $0.25 \%$ and $0.5 \%$ deltamethrin. The procedures were similar to the baseline tests to assess the mortality.

Lastly, 4\% Piperonyl Butoxide (PBO), a synergist, was used to assess the possible resistance mechanism by attempting to reverse the observed mortality outcomes [18]. Each test had four groups, each with 80 mosquitoes (in groups of 20), treated as follows: the first cohort was exposed to $4 \% \mathrm{PBO}$ for one hour and immediately exposed to deltamethrin or permethrin for $60 \mathrm{~min}$, a second group was exposed directly to the respective insecticides (i.e. deltamethrin, permethrin), a third group was exposed to the PBO only and the fourth group was exposed to control papers impregnated by silicone oil but no insecticide nor synergist. Given test kit limitations, the $\mathrm{PBO}$ tests were done only for pyrethroids.

\section{Molecular identification of sibling species of the tested mosquitoes}

Up to $10 \%$ of the mosquitoes from each bioassay were packed separately and labelled with information about experimental date, village name, type of insecticide, insecticide dose used, species of mosquito, replicate number and sample ID. The packed mosquitoes were sent to the laboratory for molecular species identification of sibling species in the An. funestus and An. gambiae s.l. complexes, using DNA extracted from the mosquito legs. Polymerase chain reaction assays were conducted based on species-specific nucleotide sequences of the ribosomal DNA (rDNA) by relying on the intergenic spacer regions (IGS) for An. gambiae sensu lato (s.l.) members and the non-coding internal transcribed spacer 2 region (ITS2) for An. funestus [52, 53]. DNA bands were photographed under ultraviolet light using Kodak Gel Logic 100 imaging system [54].

\section{Data analysis}

The data on insecticide susceptibility was interpreted based on the WHO-specified thresholds for resistance determination [18]. Susceptibility was confirmed when mortality was $\geq 98 \%$, possible resistance was determined when mortality ranged from 90 to $97 \%$, in which case the tests were repeated for confirmation, and resistance was confirmed when mortality was $<90 \%$. When mortality greater than $10 \%$ was observed in controls, the test mortality was corrected using Abbott's formula to avoid the biased estimations [55]. Tests were discarded and repeated, whenever control mortality exceeded $20 \%$ [18]. Final results were plotted in graphs using $\mathrm{R}$ software version 3.0 [56]. Log-probity analysis was used to calculate mean duration at which $50 \%\left(\mathrm{KDT}_{50}\right)$ and $95 \%\left(\mathrm{KDT}_{95}\right)$ of mosquitoes exposed to specific insecticides were knocked down.

\section{Results \\ Phenotypic resistance at baseline insecticide concentrations}

Both species were resistant to the pyrethroids (permethrin and deltamethrin) and the organochloride (DDT), but susceptible to the organophosphate (pirimiphosmethyl) at standard baseline doses $(1 \times)$. There was general susceptibility to the carbamate (bendiocarb) by both species across the study area, except in one of the villages, Tulizamoyo, where An. funestus were resistant to this insecticide. Anopheles funestus generally showed 
lower mortalities to the insecticides in the baseline tests compared to An. arabiensis (Fig. 2).

\section{Phenotypic resistance at 5 and 10 times baseline concentrations}

Anopheles funestus populations from Ikwambi and Tulizamoyo are resistant to both $5 \times$ and $10 \times$ concentrations of permethrin, but the same species from Sululu were susceptible to $10 \times$ permethrin concentrations (Fig. 3). For An. arabiensis on the other hand, resistance intensity declined with increasing insecticide concentrations. Their resistance to pyrethroids was already overcome at $5 \times$ doses in Ikwambi and Tulizamoyo villages, while the ones from Sululu village, which survived $5 \times$ doses, were overcome at $10 \times$ doses. At $10 \times$ doses, An. arabiensis from all the villages were completely susceptible to the two pyrethroids (Fig. 3). Because of the observed susceptibilities at baseline doses (Fig. 1), no intensity assays were done against pirimiphos-methyl or bendiocarb on either of the species.

\section{Knockdown times (KDT)}

Knockdown time for both mosquito species varied between insecticide and study villages. Consistently, the knockdown time slowed as the concentration increased for pyrethroid-exposed mosquitoes. Prolonged $\mathrm{KDT}_{95}$ (51-245 min) was observed to An. funestus exposed to pyrethroids compared to An. arabiensis (16-76 min), similar trend was observed on $\mathrm{KDT}_{50}$. Furthermore, the lowest knockdown time was observed when the mosquitoes were exposed to bendiocarb both at $\mathrm{KDT}_{50}$ and $\mathrm{KDT}_{95}$ for An. funestus and An. arabiensis (Table 1).

\section{Effects of pre-exposure to the synergist, $\mathrm{PBO}$}

Pre-exposure to the synergist, $\mathrm{PBO}$, significantly reversed the pyrethroid resistance in both An. arabiensis and $A n$. funestus. The PBO assays achieved mortalities $>98 \%$ in most cases, except for An. funestus populations from Sululu and Tulizamoyo villages, for which permethrinassociated mortalities were reversed past $95 \%$, but not 98\%. The synergist assays on An. arabiensis from all study areas demonstrated highest restoration of susceptibility (Fig. 4).

\section{Molecular identification of species}

After the bioassays, a total of 305 An. funestus and 144 An. arabiensis were sent to the laboratory for sibling species identification. Of all the An. funestus assessed, successful PCR amplification was $76 \%(\mathrm{n}=233)$. Of those that amplified, 99\% were An. funestus s.s. $(\mathrm{n}=232)$, while one was amplified as Anopheles leesoni. For An. gambiae s.l. successful amplification was $92 \%(\mathrm{n}=132)$, all of which were identified as An. arabiensis. The rest did not amplify in the PCR assays $(\mathrm{n}=12)$.

\section{Discussion}

In this study, both An. arabiensis and An. funestus were resistant to pyrethroids and DDT. However, An. funestus exhibited far lower mortalities when subjected to pyrethroids at either the baseline concentration, five times concentration or the ten times concentration in the

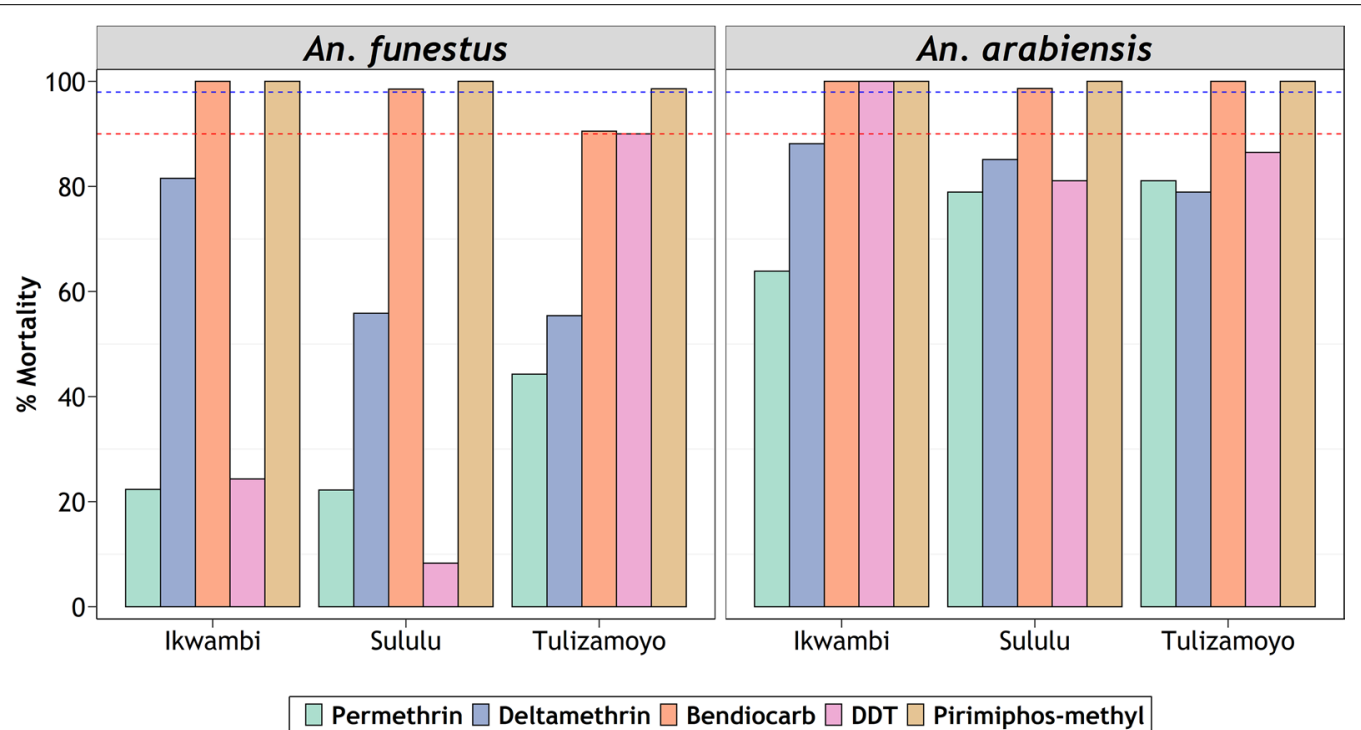

Fig. 2 Percentage mortality of Anopheles funestus (right) and Anopheles arabiensis (left) exposed to baseline concentrations of candidate insecticides. Red-dotted and blue-dotted intercepts represent $90 \%$ and $98 \%$ mortalities indicative of resistance or susceptibility, respectively 

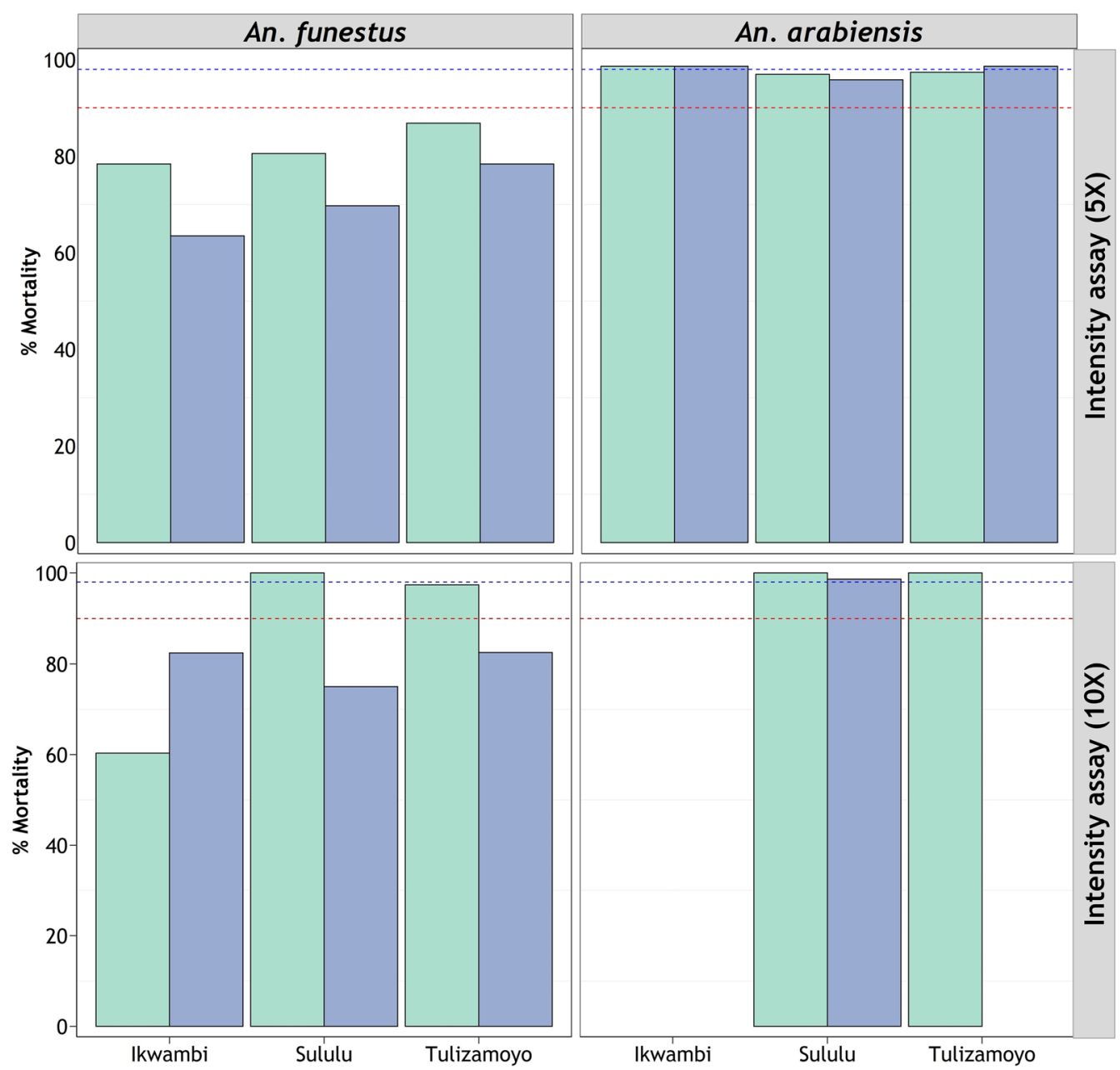

$\square$ Permethrin $\square$ Deltamethrin

Fig. 3 Resistance intensity of Anopheles funestus (right) and Anopheles arabiensis (left) under $5 \times$ and 10x baseline concentration. Red-dotted and blue-dotted intercepts represent $90 \%$ and $98 \%$ mortalities, respectively

intensity bioassays. This suggests that while An. funestus is strongly resistant to the pyrethroids, the level of resistance in An. arabiensis was either low or moderate. This is the first study to directly compare resistance intensities of these two vectors in the area, and therefore provides important information on potential performance of current or future interventions against malaria. Given the differential contribution of the two vectors to overall transmission, their responsiveness to insecticidal interventions is an important factor for consideration in the elimination efforts.

Initial findings from standard WHO susceptibility assays by Kaindoa et al. [28] and Matowo et al. [45] on the two malaria vectors in the same study area observed that the baseline mortalities were higher in An. arabiensis than An. funestus. This was the initial indication that the intensity of resistance would be different between the two species, and necessitated additional tests according to standard WHO assays [18]. The duration at which either $50 \%$ or $95 \%$ of mosquitoes would be knockeddown varied between species, insecticides and study villages (Table 1).

Knock-down time was high when mosquitoes were exposed to standard concentrations of pyrethroids, but slowed as the concentrations increased. Since no $k d r$ mutation tests were done, it is not possible to determine whether these observations were associated with the voltage-gated sodium channel protein mutation [57]. The slowest knockdown time was observed when the mosquito species were exposed to bendiocarb, these findings 
Table 1 The knockdown times of An. funestus and An. arabiensis mosquitoes at different insecticide concentrations

\begin{tabular}{|c|c|c|c|c|c|c|}
\hline \multirow[t]{2}{*}{ Insecticide } & \multirow[t]{2}{*}{ Village } & \multirow{2}{*}{$\begin{array}{l}\text { Concentration } \\
\text { (Fold) }\end{array}$} & \multicolumn{2}{|l|}{ An. arabiensis } & \multicolumn{2}{|l|}{ An. funestus } \\
\hline & & & $\mathrm{KDT}_{50} \pm \mathrm{SE}(\mathrm{min})$ & $\mathrm{KDT}_{95} \pm \mathrm{SE}(\min )$ & $\mathrm{KDT}_{50} \pm \mathrm{SE}(\mathrm{min})$ & $\mathrm{KDT}_{95} \pm \mathrm{SE}(\mathrm{min})$ \\
\hline \multirow[t]{9}{*}{ Deltamethrin } & Ikwambi & $1 \times$ & $40.87 \pm 12.55$ & $76.68 \pm 30.88$ & $77.35 \pm 50.19$ & $128.13 \pm 111.12$ \\
\hline & & $5 x$ & $8.65 \pm 6.70$ & $23.34 \pm 11.67$ & $59.03 \pm 22.43$ & $99.19 \pm 54.25$ \\
\hline & & $10 x$ & - & - & $39.06 \pm 12.85$ & $77.21 \pm 32.73$ \\
\hline & Sululu & $1 \times$ & $38.81 \pm 10.05$ & $66.76 \pm 21.76$ & $86.39 \pm 71.94$ & $132.00 \pm 146.02$ \\
\hline & & $5 x$ & $11.61 \pm 13.10$ & $47.08 \pm 23.83$ & $68.15 \pm 39.38$ & $124.38 \pm 97.13$ \\
\hline & & $10 x$ & $8.63 \pm 8.84$ & $29.22 \pm 15.50$ & $45.94 \pm 15.73$ & $87.10 \pm 41.42$ \\
\hline & Tulizamoyo & $1 \times$ & $31.30 \pm 8.82$ & $56.48 \pm 18.01$ & $152.37 \pm 388.44$ & $245.22 \pm 702.53$ \\
\hline & & $5 x$ & $16.16 \pm 5.75$ & $29.99 \pm 12.05$ & $50.54 \pm 19.60$ & $96.49 \pm 52.42$ \\
\hline & & $10 x$ & - & - & $52.53 \pm 16.60$ & $88.72 \pm 40.44$ \\
\hline \multirow[t]{9}{*}{ Permethrin } & Ikwambi & $1 \times$ & $42.19 \pm 10.82$ & $71.25 \pm 24.19$ & $104.11 \pm 124.69$ & $177.35 \pm 257.04$ \\
\hline & & $5 x$ & $6.97 \pm 5.17$ & $16.15 \pm 7.61$ & $37.62 \pm 11.07$ & $70.12 \pm 25.75$ \\
\hline & & $10 x$ & - & - & $33.21 \pm 11.87$ & $71.14 \pm 29.92$ \\
\hline & Sululu & $1 \times$ & $25.35 \pm 9.05$ & $52.67 \pm 19.02$ & $82.76 \pm 61.03$ & $130.09 \pm 127.92$ \\
\hline & & $5 x$ & $4.05 \pm 11.16$ & $25.13 \pm 15.64$ & $33.26 \pm 10.01$ & $63.31 \pm 22.11$ \\
\hline & & $10 x$ & $7.83 \pm 5.64$ & $18.93 \pm 8.92$ & $20.21 \pm 10.21$ & $51.82 \pm 21.66$ \\
\hline & Tulizamoyo & $1 \times$ & $42.80 \pm 11.56$ & $73.95 \pm 26.67$ & $70.76 \pm 41.28$ & $124.31 \pm 97.84$ \\
\hline & & $5 x$ & $6.98 \pm 8.14$ & $24.26 \pm 13.34$ & $38.32 \pm 13.87$ & $80.67 \pm 37.66$ \\
\hline & & $10 x$ & - & - & $29.16 \pm 8.61$ & $53.82 \pm 17.50$ \\
\hline \multirow[t]{3}{*}{ Pirimiphos-methyl } & Ikwambi & & $49.06 \pm 9.51$ & $70.40 \pm 20.85$ & $32.31 \pm 6.62$ & $46.15 \pm 11.89$ \\
\hline & Sululu & $1 \times$ & $57.12 \pm 10.92$ & $75.62 \pm 26.77$ & $48.30 \pm 7.54$ & $64.09 \pm 15.25$ \\
\hline & Tulizamoyo & & $53.08 \pm 14.22$ & $83.01 \pm 33.48$ & $34.03 \pm 4.70$ & $40.42 \pm 7.92$ \\
\hline \multirow[t]{3}{*}{ DDT } & Ikwambi & & $44.82 \pm 9.38$ & $67.70 \pm 19.65$ & $97.77 \pm 116.62$ & $146.48 \pm 222.68$ \\
\hline & Sululu & $1 \times$ & $55.00 \pm 11.41$ & $76.66 \pm 27.24$ & $72.33 \pm 37.37$ & $119.73 \pm 82.09$ \\
\hline & Tulizamoyo & & $61.06 \pm 23.07$ & $99.04 \pm 54.65$ & $69.53 \pm 35.24$ & $113.72 \pm 80.51$ \\
\hline \multirow[t]{3}{*}{ Bendiocarb } & Ikwambi & & $14.86 \pm 4.43$ & $24.27 \pm 9.45$ & $26.32 \pm 6.75$ & $42.21 \pm 13.04$ \\
\hline & Sululu & $1 \times$ & $19.29 \pm 4.37$ & $27.23 \pm 9.40$ & $25.18 \pm 4.92$ & $33.00 \pm 8.65$ \\
\hline & Tulizamoyo & & $16.74 \pm 3.36$ & $22.85 \pm 7.14$ & $40.42 \pm 7.61$ & $57.80 \pm 14.09$ \\
\hline
\end{tabular}

$S E$ standard error, $K D T_{50}$ time taken for $50 \%$ of the tested mosquitoes to be knocked-down, $K D T_{95}$ time taken for $95 \%$ of the tested mosquitoes to be knocked-down

still support the potency of the insecticide (Table 1). The new findings clearly demonstrate that An. funestus populations, despite being the more dominant vector of malaria in the area, would be much more difficult to control using current pyrethroid-based interventions, in particular the LLINs.

As demonstrated by Matowo et al. for both An. arabiensis and Culex mosquitoes [45, 58], there were signs of fine-scale spatial variations in insecticide resistance. For example, An. funestus populations from Tulizamoyo were resistant to bendiocarb but populations of the same species from the other two villages were susceptible to the same chemical (Fig. 2). Similarly, the mortality percentages observed at $5 \times$ and $10 \times$ doses varied between the villages (Figs. 2,3). This might be attributed to differences in the use of agricultural pesticides for crop protection in these villages [59]. Surprisingly, An. arabiensis from Ikwambi were $100 \%$ susceptible to DDT, against which both species from the other study villages were resistant
(Fig. 2), which further suggests fine-scale spatial differences in resistance profiles.

The currently observed dominance of An. funestus is likely to be contributed by their well-documented resistance to commonly used insecticides [28, 60-64], their high survival probabilities in the wild $[28,30]$ and high levels of anthropophily [28, 31, 33]. Its dominance in areas where insecticidal interventions such as ITNs are widely implemented is particularly surprising given that scale-up of ITNs has coincided with significant declines in populations of other anthropophilic vectors such as An. gambiae s.s. [41-43]. Today, in rural south-eastern Tanzania, An. funestus co-exists with other Anopheles species, namely An. arabiensis, An. leesoni, Anopheles coustani, Anopheles squamosus, Anopheles rivulorum and Anopheles pharoensis [28]. However, it is known to carry most of the ongoing malaria transmission, sometime implicating to nearly nine in every ten new cases, even in areas where it occurs in lower densities than $A n$. 


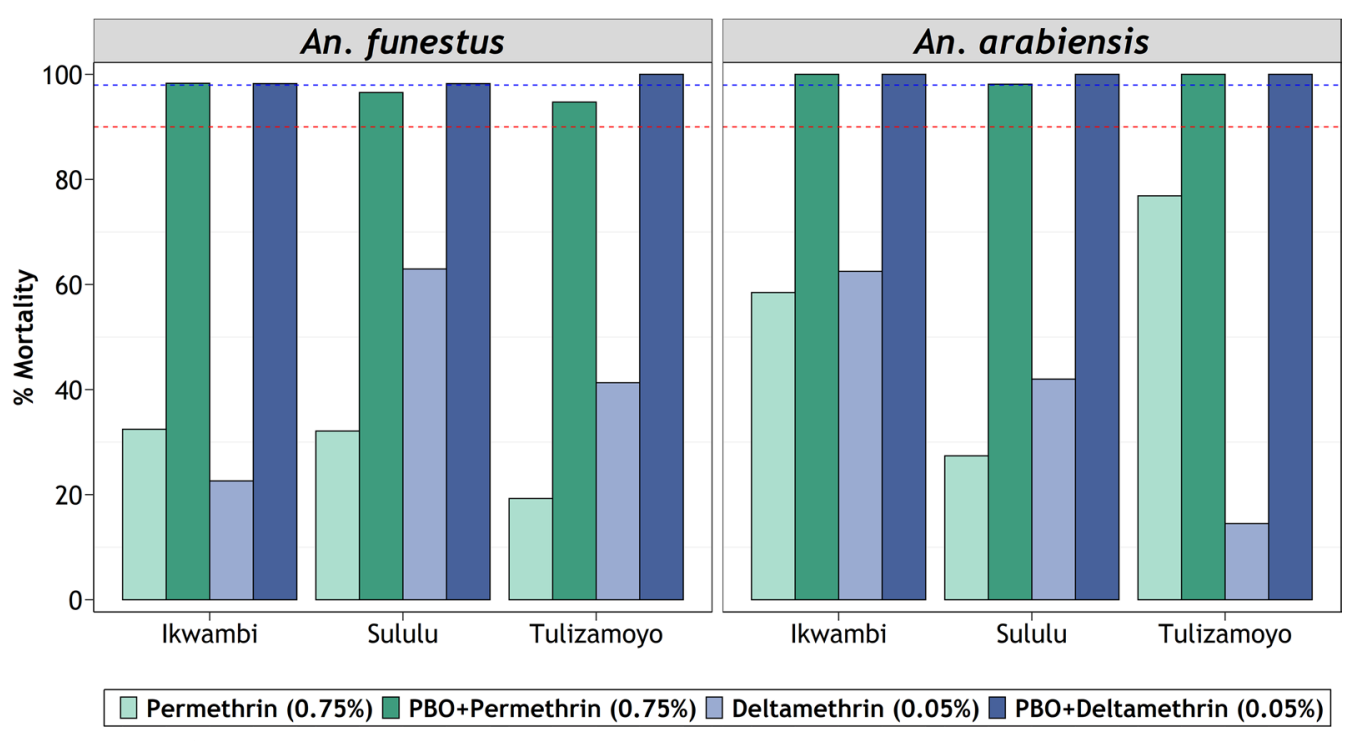

Fig. 4 Proportion mortality of Anopheles funestus and Anopheles arabiensis to pyrethroids when pre-exposed to synergist. Red-dotted and blue-dotted intercepts represent $90 \%$ and $98 \%$ mortalities, respectively

arabiensis $[28,29]$. It was thus hypothesized that its dominance may at least be partly driven by stronger insecticide resistance levels to insecticides commonly used for public health, notably the pyrethroids used on bed nets.

As insecticide resistance increases across Africa, some populations have been observed to withstand up to 1000 times the standard concentrations [65], making it an urgent need to find new classes or combinations of insecticides [3-5, 17]. In areas where An. funestus is dominant, such as in south-eastern Tanzania, the decisions on which insecticides to be implemented in vector control measures should reflect intensity of resistance in this species, even if it is difficult to find its larvae. Anopheles funestus were resistant up to ten times the WHO-recommended concentration of pyrethroids, clearly indicating that this class of insecticides can no longer be useful in the area and must be urgently replaced by other classes such as organophosphates, against which resistance is not yet detected.

The synergist tests in this study showed complete or almost complete restoration of susceptibility in the malaria vector mosquitoes nearly from all study areas. This full restoration is a likely indicator of metabolic resistance [58, 66] and suggests that ITNs which have both PBO and pyrethroids, such as PermaNet 3.0 [14] and Olyset Plus [13], may be suitable for malaria prevention in these areas, and could potentially provide better protection than standard LLINs [67]. Synergist pre-exposure combined with deltamethrin had a greater restoration in An. funestus than when the synergist was combined with permethrin (Fig. 4), but in both cases there was still substantial restoration. This could be likely due to different resistance levels against the two pyrethroid classes as observed by Rakotoson et al. [68] when An. arabiensis were pre-exposed to PBO. Partial restoration of susceptibility observed in An. funestus mosquitoes might be a sign of multiple metabolic resistance forms or other resistance mechanisms including the target-site mutation [69]. This could also be a manifestation of the demonstrated high intensities of pyrethroid resistance (Fig. 3). These findings are in line with the previous studies on the resistance of malaria vectors to pyrethroids and organochlorides and incomplete susceptibility restoration after the synergist pre-exposure to pyrethroids [68]. Nonetheless, further exploration is needed to identify the specific metabolic enzymes responsible for the observed resistance under biochemical tests. Additionally, the level of these resistant enzymes needs to be assessed using quantitative PCR assays in both An. arabiensis and An. funestus.

Despite largely achieving the stated aims, the findings of this study should be considered only as indicative and not in any way conclusive. This is due to the various methodological limitations faced during the study. First, the overall collection of the specimen was distributed over several months, and may bave been influenced by seasonal variations in resistance, as previously demonstrated [45]. Besides, given the scarcity of An. funestus specimen in some of the villages, the tests used just 120 mosquitoes. Third, this study was the use of wild mosquitoes which may have varying ages, which is an important factor long-demonstrated to impact resistance [70-72]. 
While this way of testing gives a true representation of the natural mosquito population in communities and their ability to withstand insecticidal interventions, it makes it difficult to compare the tests in a conclusive manner. The WHO guidelines recommend the use of age-synchronized $F_{1}$ generation, $3-5$ days old [18]. In this study the challenge was minimized by: (a) collecting the adult female mosquitoes at the edges of the village near potential aquatic habitats, thus maximizing the chances of getting young nulliparous mosquitoes [49], (b) adding an acclimatization period of mosquitoes for $24 \mathrm{~h}$ between the actual mosquito collection and the resistance tests, and (c) using the CDC light trap for mosquito collection, thereby capitalizing collection of nulliparous hostseeking mosquitoes [73-75]. In addition, the tests did not combine collections from multiple days, but instead used synchronized days for each replicate, thus ensuring that the mosquito ages were approximately similar. It is recognized however that these improvements slightly improved the tests but are not adequate to enable conclusive determination or comparison of resistance levels.

Another limitation was the non-amplification of the samples where $8 \%(\mathrm{n}=12)$ of An.arabiensis and $24 \%$ $(\mathrm{n}=62)$ of An. funestus complex were unidentifiable. It is possible that either there were polymorphisms in the ITS2 region of rDNA amplified in these assays, which might have been the main contributor of the observed non-amplification (Mapua et al., unpublished data), or there were a few other sibling species for which no primers were available in the assay. Future studies should involve a larger sample size, and possibly individual analysis of specimen to distinguish between species.

\section{Conclusion}

Overall, this study has demonstrated that other than the differential importance of malaria vector species and the multiplicity of malaria transmission in different settings, the responsiveness of these vectors towards different insecticides may also vary. In rural south-eastern Tanzania, An. funestus, which now dominates malaria transmission, also indicate stronger resistance to pyrethroids commonly used on ITNs than its counterpart, An. arabiensis. Despite its rarity at aquatic stage, collection methods must endeavour to find this vector with synchronized age and study its resistance profile so that effective interventions can be mounted. Lastly, the study also emphasizes that decisions on which insecticidal interventions to apply should be informed by geographical and speciesspecific studies rather than generalized studies. In this cases, it appears that PBO-based LLINs and IRS with non pyrethroids, such as organophosphates may be appropriate for now, as the main vectors are still susceptible to these treatments.

\begin{abstract}
Abbreviations
ITS2: Internal transcribed spacer 2 region; IGS: Intergenic spacer regions; IHI: Ifakara Health Institute; IRB: Institutional Review Board; LLINs: Long-lasting insecticidal nets; NIMR: National Institute for Medical Research; qPCR: Quantitative polymerase chain reaction; CDC: Centre for disease control and prevention; GSTs: Glutathione-S-transferase enzymes.
\end{abstract}

\section{Acknowledgements}

We thank the research team for their great support and volunteers who were involved in this study. We also thank our project administrator Rukiyah Mohamed Njalambaha for logistical support.

\section{Authors' contributions}

PGP, CE and FOO objective conceptualization, designed and conducted experiments, analysed the data and drafted the manuscript; DM and HSN helped in data analysis, SA helped in molecular mosquito species identification edited and revised the manuscript, JK and $\mathrm{HB}$ helped with the field mosquito collection and morphological identification. All authors read and approved the final manuscript.

\section{Funding}

The activities in this work were supported by Howard Hughes Medical Institute (HHMI) - Gates International Research Scholar award to FO (OPP1175877) and Bill \& Melinda Gates Foundation Grant (OPP1177156).

\section{Availability of data and materials}

Data available upon request.

\section{Ethics approval and consent to participate}

This study was permitted by the Institute Review Board of Ifakara Health Institute IHI/IRB/No: 19-2017 and Medical Research Coordinated Committee of the National Institute for Medical Research of the United Republic of Tanzania NIMR/HQ/R.8c/Nol. I/1185. All study household participants were recruited after signing informed consent forms.

\section{Consent for publication}

This manuscript has been approved for publication by the Institute for Medical Research of the United Republic of Tanzania NIMR/HQ/P.12 VOL XXX/.

\section{Competing interests}

Authors declare that they have no competing interests.

\section{Author details}

${ }^{1}$ Environmental Health and Ecological Sciences Department, Ifakara Health Institute, Morogoro, United Republic of Tanzania. ${ }^{2}$ Nelson Mandela African Institution of Science and Technology, School of Life Sciences and Biotechnology, Arusha, United Republic of Tanzania. ${ }^{3}$ School of Public Health, University of the Witwatersrand, Parktown, South Africa. ${ }^{4}$ Swiss Tropical and Public Health Institute, Basel, Switzerland. ${ }^{5}$ Institute of Biodiversity, Animal Health and Comparative Medicine, University of Glasgow, Glasgow, UK.

Received: 26 March 2020 Accepted: 5 November 2020

Published online: 11 November 2020

\section{References}

1. Bhatt S, Weiss DJ, Cameron E, Bisanzio D, Mappin B, Dalrymple U, et al. The effect of malaria control on Plasmodium falciparum in Africa between 2000 and 2015. Nature. 2015;526:207-11.

2. WHO. World malaria report 2019. Geneva: World Health Organization; 2019.

3. Hemingway J, Ranson H, Magill A, Kolaczinski J, Fornadel C, Gimnig J, et al. Averting a malaria disaster: will insecticide resistance derail malaria control? Lancet. 2016;387:1785-8.

4. Hemingway J. Resistance: a problem without an easy solution. Pestic Biochem Physiol. 2018;151:73-5. 
5. The malERA Refresh Consultative Panel on Insecticide and Drug Resistance. malERA: an updated research agenda for insecticide and drug resistance in malaria elimination and eradication. PLoS Med. 2017;14:e1002450.

6. Russell TL, Govella NJ, Azizi S, Drakeley CJ, Kachur SP, Killeen GF. Increased proportions of outdoor feeding among residual malaria vector populations following increased use of insecticide-treated nets in rural Tanzania. Malar J. 2011;10:80.

7. Elliott R. The influence of vector behavior on malaria transmission. Am J Trop Med Hyg. 1972;21:755-63.

8. Sougoufara S, Diédhiou SM, Doucouré S, Diagne N, Sembène PM, Harry $\mathrm{M}$, et al. Biting by Anopheles funestus in broad daylight after use of longlasting insecticidal nets: a new challenge to malaria elimination. Malar J. 2014;13:125.

9. Monroe A, Moore S, Koenker H, Lynch M, Ricotta E. Measuring and characterizing night time human behaviour as it relates to residual malaria transmission in sub-Saharan Africa: a review of the published literature. Malar J. 2019;18:6.

10. Sherrard-Smith E, Skarp JE, Beale AD, Fornadel C, Norris LC, Moore SJ, et al. Mosquito feeding behavior and how it influences residual malaria transmission across Africa. Proc Natl Acad Sci USA. 2019;1 16:15086-95.

11. WHO. Prequalification Vector Control. Geneva: World Health Organization; 2020. https://www.who.int/pq-vector-control/prequalified-lists/en/. Accessed 2 Mar 2020.

12. N'Guessan R, Odjo A, Ngufor C, Malone D, Rowland M. A chlorfenapyr mixture net interceptor ${ }^{\circledR} \mathrm{G} 2$ shows high efficacy and wash durability against resistant mosquitoes in West Africa. PLoS ONE. 2016;1 1:e0165925.

13. Protopopoff N, Mosha JF, Lukole E, Charlwood JD, Wright A, Mwalimu CD, et al. Effectiveness of a long-lasting piperonyl butoxide-treated insecticidal net and indoor residual spray interventions, separately and together, against malaria transmitted by pyrethroid-resistant mosquitoes: a cluster, randomised controlled, two-by-two fact. Lancet. 2018;391:1577-88.

14. Tungu P, Magesa S, Maxwell C, Malima R, Masue D, Sudi W, et al. Evaluation of permanet 3.0 a deltamethrin-PBO combination net against Anopheles gambiae and pyrethroid resistant Culex quinquefasciatus mosquitoes: an experimental hut trial in Tanzania. Malar J. 2010;9:21.

15. Karunaratne $P$, De Silva $P$, Weeraratne $T$, Surendran N. Insecticide resistance in mosquitoes: development, mechanisms and monitoring. Ceylon J Sci. 2018;47:299-309.

16. Hemingway J, Ranson $\mathrm{H}$. Insecticide resistance in insect vectors of human disease. Annu Rev Entomol. 2000;45:371-91.

17. Ranson $\mathrm{H}$. Current and future prospects for preventing malaria transmission via the use of insecticides. Cold Spring Harb Perspect Med. 2017;7:a026823

18. WHO. Test procedures for insecticide resistance monitoring in malaria vector mosquitoes. 2nd ed. Geneva: World Health Organization; 2018a.

19. Brogdon WG, Allister JCMC, Corwin AM, Cordon-rosales C. Independent selection of multiple mechanisms for pyrethroid resistance in Guatemalan Anopheles albimanus (Diptera: Culicidae). J Econ Entomol. 1999;92:298-302.

20. Vulule JM, Beach RF, Atieli FK. Elevated oxidase and esterase levels associated with permethrin tolerance in Anopheles gambiae from Kenyan villages using permethrin-impregnated nets. Med Vet Entomol. 1999;13:239-44

21. Chouaïbou M, Zivanovic GB, Knox TB, Jamet HP, Bonfoh B. Synergist bioassays: a simple method for initial metabolic resistance investigation of field Anopheles gambiae s.l. populations. Acta Trop. 2014;130:108-11.

22. Davies TGE, Field LM, Usherwood PNR, Williamson MS. DDT, pyrethrins, pyrethroids and insect sodium channels. IUBMB Life. 2008;59:151-62.

23. Donnelly MJ, Corbel V, Weetman D, Wilding CS, Williamson MS, Black WC IV. Does kdr genotype predict insecticide-resistance phenotype in mosquitoes? Trends Parasitol. 2009;25:213-9.

24. Liu N. Insecticide resistance in mosquitoes: impact, mechanisms, and research directions. Annu Rev Entomol. 2015;60:537-59.

25. Ingham VA, Anthousi A, Douris V, Harding NJ, Lycett G, Morris M, et al. A sensory appendage protein protects malaria vectors from pyrethroids. Nature. 2020;577:376-80.

26. Killeen GF, Seyoum A, Sikaala C, Zomboko AS, Gimnig JE, Govella NJ, et al. Eliminating malaria vectors. Parasit Vectors. 2013;6:172.

27. Cohuet A, Harris C, Robert V, Fontenille D. Evolutionary forces on Anopheles: what makes a malaria vector? Trends Parasitol. 2010;26:130-6.
28. Kaindoa EW, Matowo NS, Ngowo HS, Mkandawile G, Mmbando A, Finda $\mathrm{M}$, et al. Interventions that effectively target Anopheles funestus mosquitoes could significantly improve control of persistent malaria transmission in south—eastern Tanzania. PLoS ONE. 2017;12:e0177807.

29. Swai JK, Mmbando AS, Ngowo HS, Odufuwa OG, Finda MF, Mponzi W, et al. Protecting migratory farmers in rural Tanzania using eave ribbons treated with the spatial mosquito repellent, transfluthrin. Malar J. 2019;18:414

30. Finda MF, Limwagu AJ, Ngowo HS, Matowo NS, Swai JK, Kaindoa E, et al. Dramatic decreases of malaria transmission intensities in Ifakara, south-eastern Tanzania since early 2000s. Malar J. 2018;17:362.

31. Takken W, Verhulst NO. Host preferences of blood-feeding mosquitoes. Annu Rev Entomol. 2013;58:433-53.

32. Kiszewski A, Mellinger A, Spielman A, Malaney P, Sachs SE, Sachs J. A global index representing the stability of malaria transmission. Am J Trop Med Hyg. 2004;70:486-98.

33. Ngowo HS, Kaindoa EW, Matthiopoulos J, Ferguson HM, Okumu FO. Variations in household microclimate affect outdoor-biting behaviour of malaria vectors. Wellcome Open Res. 2017;2:102.

34. Lalji S, Ngondi JM, Thawer NG, Tembo A, Mandike R, Mohamed A, et al. School distribution as keep-up strategy to maintain universal coverage of long-lasting insecticidal nets: implementation and results of a program in southern Tanzania. Glob Health Sci Pract. 2016;4:251-63.

35. Stuck L, Lutambi A, Chacky F, Schaettle P, Kramer K, Mandike R, et al. Can school-based distribution be used to maintain coverage of long-lasting insecticide treated bed nets: evidence from a large scale programme in southern Tanzania? Health Policy Plan. 2017;32:9809.

36. Bonner K, Mwita A, McElroy PD, Omari S, Mzava A, Lengeler C, et al. Design, implementation and evaluation of a national campaign to distribute nine million free LLINs to children under five years of age in Tanzania. Malar J. 2011;10:73.

37. Renggli S, Mandike R, Kramer K, Patrick F, Brown NJ, McElroy PD, et al. Design, implementation and evaluation of a national campaign to deliver 18 million free long-lasting insecticidal nets to uncovered sleeping spaces in Tanzania. Malar J. 2013;12:85.

38. Gillies MT, Smith A. The effect of a residual house-spraying campaign in east africa on species balance in the Anopheles funestus group the replacement of $A$. funestus Giles by A rivulorum Leeson. Bull Entomol Res. 1960;51:243-52.

39. Mabaso MLH, Sharp B, Lengeler C. Historical review of malarial control in southern African with emphasis on the use of indoor residual housespraying. Trop Med Int Health. 2004;9:846-56.

40. Gillies MT, De Meillon B. The Anophelinae of Africa south of the Sahara (Ethiopian Zoogeographical Region). Johannesburg: South African Institute for Medical Research; 1968.

41. Lwetoijera DW, Harris C, Kiware SS, Dongus S, Devine GJ, McCall PJ, et al. Increasing role of Anopheles funestus and Anopheles arabiensis in malaria transmission in the Kilombero Valley. Tanzania Malar J. 2014;13:331.

42. Russell TL, Lwetoijera DW, Maliti D, Chipwaza B, Kihonda J, Charlwood $J \mathrm{D}$, et al. Impact of promoting longer-lasting insecticide treatment of bed nets upon malaria transmission in a rural Tanzanian setting with pre-existing high coverage of untreated nets. Malar J. 2010:9:187.

43. Bayoh MN, Mathias DK, Odiere MR, Mutuku FM, Kamau L, Gimnig JE, et al. Anopheles gambiae: Historical population decline associated with regional distribution of insecticide-treated bed nets in western Nyanza Province. Kenya Malar J. 2010;9:62.

44. WHO. Global report on insecticide resistance in malaria vectors: 20102016 Global Malaria Programme. Geneva: World Health Organization; 2018b.

45. Matowo NS, Abbasi S, Munhenga G, Tanner M, Mapua SA, Oullo D, et al. Fine-scale spatial and temporal variations in insecticide resistance in Culex pipiens complex mosquitoes in rural south-eastern Tanzania. Parasit Vectors. 2019;12:413.

46. Spark W. Average Weather in Ifakara, Tanzania, Year Round - Weather Spark. https://weatherspark.com/y/99526/Average-Weather-in-Ifaka ra-Tanzania-Year-Round. Accessed 3 Mar 2020.

47. Spark W. Average Weather in Mahenge, Tanzania, Year Round - Weather Spark. https://weatherspark.com/y/99524/Average-Weather-in-Mahen ge-Tanzania-Year-Round. Accessed 3 Mar 2020. 
48. Sriwichai P, Karl S, Samung Y, Sumruayphol S, Kiattibutr K, Payakkapol A, et al. Evaluation of CDC light traps for mosquito surveillance in a malaria endemic area on the Thai-Myanmar border. Parasit Vectors. 2015;8:636.

49. Smith DL, Dushoff J, McKenzie FE. The risk of a mosquito-borne infectionin a heterogeneous environment. PLoS Biol. 2004;2:e368.

50. Mboera LEG, Kihonda J, Braks MAH, Knols BGJ. Influence of centers for disease control light trap position, relative to a human-baited bed net, on catches of Anopheles gambiae and Culex quinquefasciatus in Tanzania. Am J Trop Med Hyg. 1998:59:595-6.

51. Gillies MT, Coetzee M. A Supplement to the Anophelinae of the South of the Sahara (Afrotropical Region). Publ South African Inst Med Res. 1987:55:1-143.

52. Koekemoer LL, Kamau L, Hunt RH, Coetzee M. A cocktail polymerase chain reaction assay to identify members of the Anopheles funestus (Diptera : Culicida) group. Am J Trop Med Hyg. 2002;66:804-11.

53. Collins FH. Identification of single specimen of the Anopheles gambiae complex by the polymerase chain reaction. Am J Trop Med Hyg. 1993:49:520-9.

54. Constans A. Real-time gel documentation: the KODAK Gel Logic 100 Imaging System offers gel imaging and analysis for high-throughput labs (Lab Consumer). Scientist. 2002;16:52.

55. Abbott WS. A method of computing the effectiveness of an insecticide. J Econ Entomol. 1925;18:265-7.

56. R Core Team. A language and environment for statistical computing. $R$ Foundation for Statistical Compututing. Vienna, Austria; 2019. http:// www.R-project.org/.

57. Martinez-Torres D, Chandre F, Williamson MS, Darriet F, Bergé JB, Devonshire AL, et al. Molecular characterization of pyrethroid knockdown resistance ( $k d r)$ in the major malaria vector Anopheles gambiae s.s. Insect Mol Biol. 1998;7:179-84.

58. Matowo NS, Munhenga G, Tanner M, Coetzee M, Feringa WF, Ngowo $H S$, et al. Fine-scale spatial and temporal heterogeneities in insecticide resistance profiles of the malaria vector, Anopheles arabiensis in rural south-eastern Tanzania. Wellcome Open Res. 2017;2:96.

59. Yadouleton AWM, Asidi A, Djouaka RF, Brama J, Agossou CD, Akogbeto MC. Development of vegetable farming: a cause of the emergence of insecticide resistance in populations of Anopheles gambiae in urban areas of Benin. Malar J. 2009:8:103.

60. Menze BD, Riveron JM, Ibrahim SS, Irving H, Antonio-Nkondjio C, AwonoAmbene $\mathrm{PH}$, et al. Multiple insecticide resistance in the malaria vector Anopheles funestus from Northern Cameroon is mediated by metabolic resistance alongside potential target site insensitivity mutations. PLoS ONE. 2016;11:e0163261.

61. Djouaka R, Riveron JM, Yessoufou A, Tchigossou G, Akoton R, Irving H, et al. Multiple insecticide resistance in an infected population of the malaria vector Anopheles funestus in Benin. Parasit Vectors. 2016;9:453

62. Djouaka RJ, Atoyebi SM, Tchigossou GM, Riveron JM, Irving H, Akoton R, et al. Evidence of a multiple insecticide resistance in the malaria vector Anopheles funestus in South West Nigeria. Malar J. 2016;15:565.
63. Mzilahowa T, Chiumia M, Mbewe RB, Uzalili VT, Banda ML, Kutengule A, et al. Increasing insecticide resistance in Anopheles funestus and Anopheles arabiensis in Malawi, 2011-2015. Malar J. 2016;15:563.

64. Riveron JM, Osae M, Egyir-Yawson A, Irving H, Ibrahim SS, Wondji CS. Multiple insecticide resistance in the major malaria vector Anopheles funestus in southern Ghana: implications for malaria control. Parasit Vectors. 2016;9:504

65. Toé KH, Jones CM, N'fale S, Ismai HM, Dabiré RK, Ranson H. Increased pyrethroid resistance in malaria vectors and decreased bed net effectiveness Burkina Faso. Emerg Infect Dis. 2014;20:1691-6.

66. Zoh DD, Ahoua Alou LP, Toure M, Pennetier C, Camara S, Traore DF, et al. The current insecticide resistance status of Anopheles gambiae (sl) (Culicidae) in rural and urban areas of Bouaké. Côte d'Ivoire Parasit Vectors. 2018;11:118.

67. Gleave K, Lissenden N, Richardson M, Choi L, Ranson H. Piperonyl butoxide (PBO) combined with pyrethroids in insecticide-treated nets to prevent malaria in Africa. Cochrane Database Syst Rev. 2018;1101:2776.

68. Rakotoson JD, Fornadel CM, Belemvire A, Norris LC, George K, Caranci A, et al. Insecticide resistance status of three malaria vectors, Anopheles gambiae (s.l.), An. funestus and An. mascarensis, from the south, central and east coasts of Madagascar. Parasit Vectors. 2017;10:396.

69. Nwane P, Etang J, Chouabou M, Toto JC, Koffi A, Mimpfoundi R, et al. Multiple insecticide resistance mechanisms in Anopheles gambiae s.l. populations from Cameroon Central Africa. Parasit Vectors. 2013;6:41.

70. Kulma K, Saddler A, Koella JC. Effects of age and larval nutrition on phenotypic expression of insecticide-resistance in Anopheles mosquitoes. PLOS ONE. 2013;8:e58322

71. Chouaibou MS, Chabi J, Bingham GV, Knox TB, N'Dri L, Kesse NB, et al. Increase in susceptibility to insecticides with aging of wild Anopheles gambiae mosquitoes from Côte d'Ivoire. BMC Infect Dis. 2012;12:214.

72. Glunt KD, Thomas MB, Read AF. The effects of age, exposure history and malaria infection on the susceptibility of Anopheles mosquitoes to low concentrations of pyrethroid. PLoS ONE. 2011;6:e24968.

73. Mboera LE. Sampling techniques for adult Afrotropical malaria vectors and their reliability in the estimation of entomological inoculation rate. Tanzan Health Res Bull. 2005;7:117-24.

74. Sadanandane C, Jambulingam P, Subramanian S. Role of modified CDC miniature light-traps as an alternative method for sampling adult anophelines (Diptera: Culicidae) in the National Mosquito Surveillance Programme in India. Bull Entomol Res. 2004;94:55-63.

75. Lines JD, Curtis CF, Wilkes TJ, Njunwa KJ. Monitoring human-biting mosquitoes (Diptera: Culicidae) in Tanzania with light-traps hung beside mosquito nets. Bull Entomol Res. 1991;81:77-84.

\section{Publisher's Note}

Springer Nature remains neutral with regard to jurisdictional claims in published maps and institutional affiliations.
Ready to submit your research? Choose BMC and benefit from:

- fast, convenient online submission

- thorough peer review by experienced researchers in your field

- rapid publication on acceptance

- support for research data, including large and complex data types

- gold Open Access which fosters wider collaboration and increased citations

- maximum visibility for your research: over $100 \mathrm{M}$ website views per year

At BMC, research is always in progress.

Learn more biomedcentral.com/submissions 